\title{
Difficulties in the Management of Civilian Peripheral Vascular Trauma and their Complications at the University Teaching Hospital of Yaoundé, Cameroon
}

\author{
Ngo Nonga $B^{1,2 *}$, Savom EP ${ }^{2}$, Bang GA 1 , Londji GM ${ }^{1}$ and Essomba AG ${ }^{1,2}$ \\ ${ }^{1}$ Service of surgery, University Teaching Hospital of Yaoundé, Cameroon \\ ${ }^{2}$ Department of Surgery and Specialities, Faculty of Medicine and Biomedical Sciences, University of Yaoundé I, Cameroun
}

\begin{abstract}
Background: The incidence of peripheral vascular lesions remains undetermined in Cameroon. The objective of this study was to report our experience with the management of peripheral vascular trauma in civil life at the University Teaching Hospital of Yaoundé.
\end{abstract}

Patients and methods: We have reviewed retrospectively all the cases of peripheral vascular trauma treated at the Yaoundé's University Teaching Hospital between 2008 and 2010. We excluded all patients with crushing members or traumatic amputations. Case notes were reviewed for demographic factors, nature of trauma, vascular injury observed and treatment applied.

Results: We found 12 patients on 2,436 traumas giving a prevalence of $0.5 \%$. There were 11 men and one woman, mean age was $28.5(18-55)$ years. All patients were victims of a penetrating wound. Nine patients were received at the stage of complications from 6 weeks to 2 years after the trauma: 5 of them had arteriovenous fistulas and the other four presented with pseudo aneurysms, they were all operated successfully. Three patients came in emergency at the time of the injury and they presented lesions to the popliteal vessels, brachial and radial arteries. They were amputated after a failed attempt revascularization performed beyond 6 hours after trauma.

Conclusion: Vascular injuries are usually overlooked in our environment, and we would recommend a vascular exam in patients with penetrating injuries to the limb to avoid missing them.

Keywords: Penetrating injury; Peripheral vascular trauma; Pseudoaneurysm; Arteriovenous fistula

\section{Introduction}

Peripheral vascular injuries are very common and result most often from penetrating wounds [1-3]. The management of these lesions is a big challenge for practitioners because it requires urgent action to preserve vital prognosis and reduce morbidity. In addition, some severe lesions present only with occult symptoms and signs and are often overlooked, manifesting later by signs of vascular insufficiency, pseudo-aneurysm or arteriovenous fistula [1-3]. Vascular lesions are readily combined with other injuries or enrol in a context of multiple injuries. Other lesions, often impressive, then mask the vascular wound with a consequent increase in morbidity and mortality. The actual incidence of these lesions in Cameroon and Sub-Saharan Africa is unknown because few studies have been published on this topic. However, the increase of criminality in Cameroon with common increasingly use of firearms and bladed weapons has increased the incidence of vascular lesions [4].

Like in most developing countries, Cameroon lacks effective resources for the management of emergencies, especially trauma related emergencies, the result being late arrival of these patients in health centres and moreover, we lack qualified human resources. Some vascular lesions, often obvious, thus pass unnoticed. Effective management of vascular lesions must be immediate and involves early recognition of these lesions. To these shortcomings, are added the existence of traditional caregivers who attract a large number of patients and the lack of health insurance, which often delay the care of these patients even when the diagnosis is made early. These diagnostic and therapeutic delays result in the production of irreversible ischemic lesions that can lead to functional impairment or amputation [5]. The aim of this study was to report our experience in the management of peripheral vascular traumatic lesions and to describe the symptoms and signs that may raise suspicion about the existence of a vascular injury in our environment where infrastructures and qualified medical resources are often lacking.

\section{Patients and Methods}

From July 2008 to December 2010, we retrospectively reviewed the medical records of all patients admitted for a penetrating peripheral vascular trauma in civil life at the University Teaching Hospital of Yaoundé. We included in the study all patients with traumatic injury of peripheral vessels with or without associated lesions and whatever the delay occurred. Patients with crushing injuries, blunt injuries or patients who required amputation at admission were excluded. The diagnosis was essentially clinical: pulselessness, coldness of the extremity, pain, paraesthesia, paralysis, pulsatile mass, bruit or thrill, wound in the anatomical region of the vessels, important bleeding and

*Corresponding author: Ngo Nonga B, Department of Surgery and Specialities, Faculty of Medicine and Biomedical Sciences, University of Yaoundé I, Cameroun Tel:+237222221320; E-mail: ngonongab@yahoo.com

Received November 03, 2016; Accepted November 30, 2016; Published December 07, 2016

Citation: Ngo Nonga B, Savom EP, Bang GA, Londji GM, Essomba AG (2016) Difficulties in the Management of Civilian Peripheral Vascular Trauma and their Complications at the University Teaching Hospital of Yaoundé, Cameroon. J Vasc Med Surg 4: 292. doi: 10.4172/2329-6925.1000292

Copyright: (c) 2016 Ngo Nonga B, et al. This is an open-access article distributed under the terms of the Creative Commons Attribution License, which permits unrestricted use, distribution, and reproduction in any medium, provided the original author and source are credited. 
a non- healing wound with bloody discharge without signs of infection. All patients underwent open surgery and vascular repair consisting of direct suture in case of lateral wound, anastomosis when the defect was less than $2 \mathrm{~cm}$ and beyond, we realised an inverted saphenous graft interposition for larger defects. The non-vital vessels were ligated. In case of associated lesions, vascular repair preceded the treatment of other injuries. Large veins were always repaired. Postoperative followup was essentially clinical.

Case notes of all the patients were reviewed for demo-graphic profile (age, gender), time to admission, mechanism and location of injury, types of lesions, associated injury, repair techniques and results of treatment. Statistical analysis was performed using SPSS 9.0 software and the study received approval from the Ethics Committee of the University of Yaoundé I.

\section{Results}

\section{Demographics}

From July 2008 to December 2010, we identified 2,436 trauma patients including 12 with penetrating peripheral vascular injury of the civil life giving a prevalence of $0.5 \%$. There were 11 men and one woman with a sex ratio of 11 . The mean age was $28.5(18-55)$ years.

\section{Mechanism of injury and time to consultation}

All patients were victims of a penetrating wound of a peripheral vessel: 4 by gunshots and 8 by bladed weapons. The consultation periods ranged from 1 day to 2 years (Table 1). Only three patients were seen at the moment of the trauma in acute situation, the other 9 were received after complications have occurred (Table 2).

\section{Sites and types of vascular injury}

Four (33.33\%) patients had an injury to the upper limb, 7 (58.33\%) patients to the lower extremity and one $(8.33 \%)$ patient had an injury to the temporal region. There were 5 femoral lesions, 2 brachial, 2 popliteal and one lesion each of radial, ulnar and temporal arteries (Table 1). Eight patients had associated venous lesions including 5 cases of arteriovenous fistulas and 3 cases of venous lesions accompanying arteries. Four of the five femoral lesions were associated with an arteriovenous fistula between the femoral vein and deep femoral artery and complicated with a pseudo aneurysm at the bifurcation. A 22-yearold man had an arteriovenous fistula between the brachial artery and the vein comitans associated with a giant pseudo-aneurysm of the vein comitias (Figure 1). Patients seen at the stage of complications had a pulsatile mass of variable diameter (pseudo-aneurysm) sometimes

\begin{tabular}{|l|c|c|}
\hline \multicolumn{1}{|c|}{ Time before consultation } & Number of patients & Percentage \\
\hline 0-2 days & 3 & 0.25 \\
\hline$<1$ month & 1 & $8,33 \%$ \\
\hline 1-3 months & 6 & 0.5 \\
\hline 3 months-1 year & 1 & $8,33 \%$ \\
\hline >1 year & 1 & $8,33 \%$ \\
\hline Total & 12 & 1 \\
\hline
\end{tabular}

Table 1: Time elapsed from the injury to consultation.

\begin{tabular}{|l|c|c|}
\hline \multicolumn{1}{|c|}{ Mechanism } & Number of patients & Percentage \\
\hline Gunshot & 4 & $33,33 \%$ \\
\hline $\begin{array}{l}\text { Bladed weapons (knife, } \\
\text { machete, rasor) }\end{array}$ & 8 & $66,66 \%$ \\
\hline Total & 12 & 100 \\
\hline
\end{tabular}

Table 2: Mechanisms of injuries.

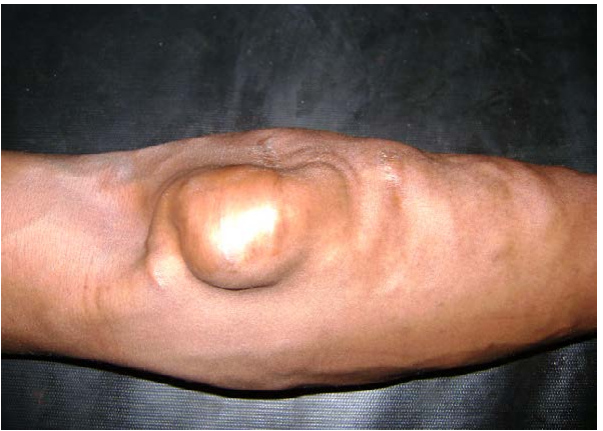

Figure 1: Posttraumatic arteriovenous fistula between the brachial artery and the vein comitans with a large pseudo-aneurysm and massively distended superficial veins.

associated with a tremor (thrill) in the case of arteriovenous fistula and sometimes chronic bleeding without signs of infection?

The 3 patients seen immediately after the accident (from $20 \mathrm{~h}$ to 48 $\mathrm{h}$ after the injury) showed obvious signs of ischemia: pain, coldness, pulselessness, paraesthesia and paralysis, in addition to massive bleeding.

\section{Associated injuries}

Nerve lesions were found in a patient in the upper limb (median and radial nerves at the elbow) and two patients with popliteal lesions had communitive fractures of the femoral condyles.

All other patients with complications had isolated lesions.

All diagnosis were done clinically: duplex ultrasound scanning is available in some places in Yaoundé but not in an emergency setting and it is expensive, so very few patients can afford to pay for it.

\section{Treatment}

Reconstructive surgery was performed for all lesions of large vessels (Table 3). Regarding arterial lesions, we used a saphenous vein interposition in 3 cases, repair (suture and anastomosis) in 5 cases and a ligation was performed for isolated lesions of radial, ulnar and temporal arteries. All large veins were repaired. At the femoral level, we had in one case to tie the deep femoral artery because of bleeding and difficulties during surgery but the femoral vein was repaired. This ligation had no impact on the limb irrigation.

In patients with acute lesions, two had combined lesions of the popliteal artery and vein with communitive fractures of the femoral condyles secondary to gunshots. The repair took place respectively 20 and 96 hours after the trauma. We used saphenous vein taken from the opposite side in both cases to repair the popliteal artery with a simple repair of the vein. Not having been able to realize a thrombectomy due to lack of Fogarty catheter, we refrained to perform a fasciotomy.

\section{Outcomes}

We had no deaths. Nine patients with chronic complications had a favourable evolution with a mean length of hospital stay of 3 days duration.

All three patients seen acutely were amputated and the mean length hospital stay was 2 weeks. The two patients with popliteal lesion associated with femoral condyle fractures developed wet gangrene requiring amputation respectively four days and one week postoperatively. A patient with a partial amputation secondary to a 
Citation: Ngo Nonga B, Savom EP, Bang GA, Londji GM, Essomba AG (2016) Difficulties in the Management of Civilian Peripheral Vascular Trauma and their Complications at the University Teaching Hospital of Yaoundé, Cameroon. J Vasc Med Surg 4: 292. doi: 10.4172/2329-6925.1000292

Page 3 of 4

\begin{tabular}{|l|l|l|l|l|}
\hline \multicolumn{1}{|c|}{ Type of lesions } & Number of cases & \multicolumn{1}{c|}{ Location } \\
\hline Isolated pseudoaneurysms & 3 & Procedure & Temporal, radial and ulnar arteries \\
\hline Multiple pseudoaneurysms & 1 & Superficial femoral & Resection and saphenous interposition \\
\hline Pseudoaneurysm with arteriovenous fistula & 4 & $\begin{array}{l}\text { Deep femoral artery - common } \\
\text { femoral vein }\end{array}$ & $\begin{array}{l}\text { Repair of both deep femoral artery and } \\
\text { femoral vein }\end{array}$ \\
\hline Arteriovenous fistula and venous pseudoaneurysm & 1 & $\begin{array}{l}\text { Resection of venous pseudoaneurysm } \\
\text { and artery repair }\end{array}$ & $\begin{array}{l}\text { Brachial and radial vessels (1), } \\
\text { popliteal vessels (2) }\end{array}$ \\
\hline Artery and vein wounds & 3 & revascularization & \\
\hline
\end{tabular}

Table 3: Type, location of lesions and type of surgical treatment.

machete had a transection of the brachial and radial arteries associated with a lesion of the median and radial nerves at the elbow and had an amputation two days after a failed attempt revascularization performed 24 hours after the trauma. This gives an amputation rate of $100 \%$.

\section{Discussion}

Very few studies have been devoted to vascular trauma in Sub-Saharan Africa in general and in Cameroon in particular and peripheral vascular lesions are often overlooked in this sub-region [1]. Male predominance due to the predominance of trauma in general in men compared to women is the same as in the literature [1-8]. The young age of our patients is also found in several studies. All vascular lesions identified in this study are the results of penetrating wounds. This is consistent with literature data where penetrating injuries represent more than $2 / 3$ of injuries in the limbs [1-3]. Mommsen et al. [6], however, found penetrating wounds in only $31.8 \%$ of cases and Jawas et al. [7] reported stab lesions in $57 \%$ of cases. These findings in our series, although in the line with that of many authors, could be explained by the increase in criminality in our country associated to an increase use of firearms ( 4 cases) and bladed weapons ( 8 cases). There is a preponderance of the lower limb lesions as reported in the literature $[2,6,7,9,10]$. We have found only 3 cases associated with bone and nerve lesions. Bone and nerve lesions have been the most commonly reported associated lesions in several publications $[1,2,7,8]$. Aduful et al. in Ghana [1] found further significant muscle injuries in $21.2 \%$ of cases.

We collected a large number of late complications (9 cases) with respect to acute vascular injuries (3 cases). If these findings have become rare elsewhere, they reflect the weakness of our health system where signs and symptoms of vascular diseases are not well recognized by unqualified personal. All these patients have consulted at the time of the injury in an emergency basis and 7 out of 9 patients who presented with late complications have been transfused 2 to 4 units of blood at the time of accident without raising suspicion about the possibility of a vascular injury. Patients were referred to us when a complication became visible and troublesome (Figure 1) and in most cases there were bleeding pseudo aneurisms. This late diagnosis has been described by Adulful et al. in Ghana [1] and is due to unavailability of vascular surgeons in our country where there are few specialists all concentrated in the only city of Yaoundé.

Of the 5 patients with femoral lesions, 4 had an arteriovenous fistula just after the division of the common femoral artery between the deep femoral artery and the femoral vein; lesion rarely reported in the literature. One of the patients in this serie have been reported an unusual case of giant pseudo-aneurysm of the vein comitans following a posttraumatic arteriovenous fistula between this vein and the brachial artery with distension of all the superficial veins and painful swelling of the upper limb [11]. We found a reported case of arteriovenous fistula between brachial artery and vein comitans with an expansion of the artery rather than the vein as in our case [12]. Venous pseudoaneurysms are rarely reported in the literature [13].

Given the lack of appropriate and complex infrastructures such as arteriography, MRI angiography and the fact that CT angiogram and Doppler ultrasound are not always available in emergency, our diagnostic approach was essentially based on clinical, in particular, the six P's of ischemia: pain, pulselessness, pallor, paraesthesia's, poikilothermic and paralysis. The existence of these signs reinforces the diagnosis, but they are not always present. Clinical signs of vascular injuries can be divided into hard signs, for which predictive positive value of vascular injury is close to $100 \%$ [14] and soft signs with possibility of arterial injury. Hard signs include distal cold ischemic extremity, absent pulses, bruit or thrill, expanding or pulsatile haematoma and pulsatile bleeding. Soft signs are made up of nonexpanding haematomas, paraesthesia/ paresis, shock (unexplained by other injuries), decreased pulses and proximity of penetrating wound to major vascular structures. In these clinical signs of vascular disease which were frequently found in our patients, we have added limb isolated penetrating wound, major bleeding requiring transfusion, and persistence of haematic drainage at the level of a penetrating wound beyond ten days and in the absence of obvious infectious signs. Complementary investigations whenever possible and affordable may be done in some centres in chronic lesions with arteriovenous fistula or pseudo-aneurysm, in acute settings and in the presence of major signs of vascular injury, these examinations whose contribution is not always important in therapeutic decision urgently, have no interest. They could further delay an urgent lifesaving treatment procedure. Although we can recognize with some authors that angiography is useful to locate the vascular lesion in case of multiple external injuries [15], however, clinical examination has proved its primacy on diagnostic arteriography in the diagnosis of acute vascular lesions as reported in some studies $[16,17]$.

All patients were operated by open surgery. If endovascular techniques (embolization, stenting) are widely used in the Western world for some vascular injuries [18], open surgery keeps a place of choice for many authors with good results [6-9]. However, endovascular techniques in properly selected patients offer many advantages. They reduce operating time and blood loss, limit dissection of bruised or injured tissues by the initial trauma and allow access to hard-to-reach areas with good safety and acceptable efficiency [10]. In cases where the final repair is not possible, they allow control of bleeding or damage and facilitate the surgical procedure [18].

Our results were satisfactory with 9 cases of favourable outcome after surgical repair of damaged vessels. However, we noted 3 cases of amputations in the 2 patients with popliteal lesions and the patient with brachial artery injury. The rate of amputation was $100 \%$ in acute setting very far from the one reported in the literature $[1,3,8,10,11]$. Revascularization procedure failed because patients came in late, they were operated more than 20 hours after the injury, there was no Fogarty catheter to remove distal clots. These patients had associated 
injuries, bone lesions for the first two and nerve for the third and were operated beyond the recommended time. The association with other lesions, particularly bones and nerves and the delay of treatment are the main risk factors for amputation found in the literature $[1,3,8,10,12]$. Some lesions as popliteal artery injury have a high risk of amputation that may exceed $50 \%$ in the study of Li et al. [10]. To the reported risk factors of amputation in the literature, we can add local risk factors such as poverty which often prolongs the time of consultation and treatment, ignorance of acute injury by unskilled medical staff and lack of adequate equipment. In this environment where expertise and technical resources are lacking, the focus should be on popularization of vascular surgery which involves teaching and funding by the government to improve the management of trauma in general and vascular injuries in particular.

\section{Conclusion}

Peripheral vascular injuries are often overlooked and most patients are received at the stage of complications despite the often obvious clinical signs and this because of poverty and lack of skilled human resources. The management faces the same difficulties that add technological backwardness. Despite these failures, the management of these injuries can be performed in Cameroun with results closed to those reported in the literature. Hope lies in the creation of a sub specialization in vascular surgery.

\section{References}

1. Aduful HK, Hodasi WM (2007) Peripheral vascular injuries and their management in accra. Ghana Medical Journal 41: 186-189.

2. Krüger A, Florido C, Baunisch A, Walther E, Yilmaz TH, et al. (2013) Penetrating arterial trauma to the limbs: outcome of a modified protocole. World Journal of Emergency Surgery 8: 51.

3. Topal AE, Eren MN, Celik Y (2010) Lower extremity arterial injuries over a sixyear period: outcomes, risk factors and management. Vascular Health and Risk Management 6: 1103-1110.

4. Bahebeck J, Atangana R, Mboudou E, Ngo Nonga B, Sosso MA, et al. (2005) Incidence, case-fatality rate and clinical pattern of injuries in two cities where arm owning is forbidden Injury. Int $\mathrm{J}$ care Injured 36: 714-717.

5. Yousuf KM, Bhagwani AR, Bilal N (2013) Management of chronic traumatic arteriovenous fistula of the lower extremities. Eur J Trauma Emerg Surg 39: $393-6$
6. Mommsen P, Zeckey C, Hildebrand F, Frink M, Khaladj N, et al. (2010) Traumatic extremity arterial injury in children: Epidemiology, diagnostics, treatment and prognostic value of Mangled Extremity Severity Score. Journal of Orthopaedic Surgery and Research 5: 25.

7. Jawas A, Hammad F, Eid HO, Abu-Zidan FM (2010) Vascular injuries following road traffic collisions in a high-income developing country: a prospective cohort study. World Journal of Emergency Surgery 5: 13.

8. De Silva WDD, Ubayasiri RA, Weerasinghe CW, Wijeyaratne SM (2011) Challenges in the management of extremity vascular injuries: A wartime experience from a tertiary centre in Sri Lanka. World Journal of Emergency Surgery 6: 24 .

9. Khan FH, Yousuf KM, Bagwani AR (2015) Vascular injuries of the extremities are a major challenge in a third world country. Journal of Trauma Management \& Outcomes 9: 5 .

10. Li Z, Zhao L, Wang K, Cheng J, Zhao Y, et al. (2014) Characteristics and treatment of vascular injuries: a review of 387 cases at a Chinese center. Int J Clin Exp Med.7: 4710-4719.

11. Daniel HE, Firmin A, Angele P, Esthelle MN, Freddy B, et al. (2015) Giant pseudoanerysm associated with arteriovenous fistula of the brachial and femoral arteries following gunshot wounds: report of two cases. Cases Report in Vascular Medicine.

12. Loughlin V, Beniwal JS (1988) Post-traumatic brachial artery aneurysm and arteriovenous fistulae. J Cardiovasc Surg (Torino) 29: 570-571.

13. Kuhlencordt $P J$, Linsenmeyer $U$, Rademacher $A$, sadeghi-Azandaryani $M$ Steckmeier B, et al. (2008) Large external iliac vein aneurysm in a patient with a post-traumatic femoral arterioveinous fistula. J Vasc Surg. 47: 205-208.

14. Krykberg ER, Dennis JW, Bishop K, Laneve L, Alexander RH (1991) The reliability of physical examination in the evaluation of penetrating extremity trauma for vascular injury: results at one year. J Traume 31: 502-511.

15. Ramanathan A, Perera DS, Sheriffdeen AH (1995) Emergency femoral arteriography in lower limb vascular trauma. Ceylon Med J 40: 105-106.

16. Dennis JW, Frykberg ER, Veldenz HC, Huffman S, Menawat SS (1998) Validation of nonoperative management of occult vascular injuries and accuracy of physical examination alone in penetrating extremity trauma: 5 - to 10-year follow-up. J Trauma 44: 243-252.

17. Gillespie DL, Woodson J, Kaufman J, Parker J, Greenfield A, et al. (1993) Role of arteriography for blunt or penetrating injuries in proximity to major vascular structures: an evolution in management. Ann Vasc Surg 7: 145-149.

18. Johnson CA (2010) Endovascular management of peripheral vascular trauma Seminars in Interventional radiology 27: 38-43. 